\title{
An investigation of hydrogen-fuelled HCCI engine performance and operation*
}

\author{
J.M. Gomes Antunes, R. Mikalsen, A.P. Roskilly ${ }^{\dagger}$ \\ Sir Joseph Swan Institute for Energy Research, Newcastle University, United Kingdom.
}

\begin{abstract}
This paper presents the findings of an experimental investigation into the operation of a compression ignition (CI) engine in homogeneous charge compression ignition (HCCI) mode using hydrogen fuel. Factors that were investigated include engine efficiency, emissions and mechanical loads. Hydrogen was found to be a possible fuel for operation of a CI engine in HCCI mode. The heat release rate is extremely high, which leads to high ignition timing control requirements. The ignition timing was controlled using heating of the inlet air, and satisfactory performance was demonstrated using this method. Some cycle-to-cycle variations were, however, observed due to the difficulty in achieving accurate control of ignition timing.

Use of hydrogen in HCCI engines allows operation with very lean air-fuel mixtures, giving extremely low emissions of nitrogen oxides and other pollutants. Operation with an excess air ratio of 6 was demonstrated, and a maximum fuel efficiency of $45 \%$ was achieved with an excess air ratio of 3 . The maximum power of the engine in HCCI mode is, however, quite modest, being limited by the need for inlet air heating to ensure auto ignition, which reduces the air mass flow through the engine. There are also mechanical limitations to the operation of the HCCI hydrogen engine at high loads due to higher rates of pressure rise and in-cylinder peak pressures compared to conventional diesel mode.
\end{abstract}

\section{Introduction}

For more than a century, hydrocarbon fuels have played a leading role in propulsion and power generation. Recent years, declining oil reserves and increased fuel prices have, together with increased awareness of the environmental impacts of burning hydrocarbon fuels, led to an interest in alternatives to fossil fuel based propulsion and power generation. One such alternative is to use hydrogen as an energy carrier and to extract energy using a fuel cell or a modified internal combustion engine. Some hydrogen production technologies are well known, mature and well-developed. Still, a number of concerns over the conversion technologies need to be addressed in relation to power to weight ratio, price, reliability, storage and transportation.

CI engines running with lean hydrogen/air mixtures have been operated with higher efficiencies than the same engine operated with direct injection of diesel oil $[1,2]$. Low combustion temperatures under those lean conditions limit the formation of $\mathrm{NO}_{x}$ emissions. This paper investigates the potential of a naturally aspirated, CI, hydrogen fuelled engine with external mixture formation.

\subsection{The HCCI mode of operation}

Homogeneous Charge Compression Ignition (HCCI) has been under intense investigation due to its potential to reduce engine $\mathrm{NO}_{x}$ and particulate emissions whilst still maintaining a high thermal efficiency. In the literature, this type of engine cylinder charge formation is known by various names: Controlled Auto Ignition (CAI), Lean Homogeneous Combustion (LHC), Compression Ignited Homogeneous Charge Combustion (CICH), Active Radical Combustion (ARC), Homogeneous Charge Compres-

${ }^{*}$ This is a preprint version. This paper was published as: International Journal of Hydrogen Energy 2008;33:5823-5828.

${ }^{\dagger}$ Corresponding author. Address: Sir Joseph Swan Institute for Energy Research; Newcastle University; Newcastle upon Tyne; NE1 7RU; United Kingdom. Tel. +44 191222 5869; fax +44 191222 8533. Email: tony.roskilly@ncl.ac.uk. sion Ignition Diesel Combustion (HCDC), Diesel Fumigation, Multiple Staged Diesel Combustion (MULDIC), and Premixed Compression Ignited Combustion (PCIC).

This method has been applied to both four and two stroke, medium and high speed engines, with various fuels being investigated. The HCCI process involves the premixed fuel/air charge being introduced into the cylinder at equivalence ratios between 0.15 and stoichiometric [3]. Once inside the cylinder the charge is compressed, during which the ignition temperature of the charge is reached. The ignition occurs simultaneously at multiple points around the cylinder, resulting in very fast combustion and enabling all the heat to be released within a short time space. A minimum of 4 crank angle degrees has been reported [4,5].

One of the benefits of the HCCI mode is the elimination of fuel rich and high temperature zones in the cylinder, which are responsible for formation of exhaust emissions, in particular nitrogen oxides and particulates [6]. Since the HCCI engine depends on the cylinder charge autoigniting, the use of high compression ratios is required. With no charge heating, this was found to be between 18:1 and 25:1 when carrying out simulation studies for the engine used in this study. Conventional spark ignition engines are typically limited to a compression ratio of approximately 10:1. The combination of fast heat release in HCCI mode and the use of a lean cylinder charge, gives close to constant volume combustion with low peak gas temperatures leading to reduced heat transfer losses through the cylinder walls and high indicated thermal efficiencies.

\subsection{Hydrogen as a fuel}

Hydrogen possesses some features that make it attractive for use as a fuel in internal combustion engines, enabling fast, close to constant volume combustion, high combustion efficiency and low emissions. Numerous authors have investigated the use of hydrogen in spark ignition (SI) engines, and the feasibility of hydrogen as a fuel in 
such engines is well established. An overview of the characteristics of hydrogen as a fuel for SI engines was presented by Karim [7].

The flame speed of hydrogen is higher and hydrogen allows operation at significantly higher excess air ratios than conventional hydrocarbon fuels. This enables extended lean burn operation of the engine, potentially leading to a drastic reduction of $\mathrm{NO}_{x}$ emissions. High diffusivity and low quenching distance avoids poor vaporisation problems.

Emissions of carbon monoxide and unburnt hydrocarbons are practically eliminated with a hydrogen fuelled engine, as the only source of carbon will be the lubricating oil. For the same reason the engine does not emit carbon dioxide. The only non-trivial exhaust gas emissions will be nitrogen oxides, which result from the oxidation of atmospheric nitrogen under high temperatures. It will be shown below that with HCCI operation and a very lean mixture this pollutant can be reduced to near-zero levels.

The ignition energy for hydrogen is low, however the temperature required for autoignition is significantly higher than that of conventional hydrocarbon fuels. Therefore, CI engines using hydrogen fuel require high compression ratios and/or pre-heating of the inlet air to ensure autoignition. The latter was used in this study, and is discussed below.

A comprehensive review of hydrogen-fuelled internal combustion engines was presented by White et al. [8].

\section{Research engine and experimen- tal setup}

The engine used on this research work was a four-stroke, single cylinder, direct injection, naturally aspirated, air cooled CI engine. The engine was coupled to a hydraulic pump system so that the engine could be operated at varying load conditions. The engine was fitted with an injection system allowing hydrogen to be mixed with the inlet air. Using this setup, the performance of the engine operating in hydrogen fuelled HCCI mode and normal diesel fuelled mode could be investigated and compared. Table 1 gives the design data for the engine used in the experimentation reported in this paper.

Hydrogen was injected close to the inlet valve port using a fast response solenoid valve and an injection controller. The maximum hydrogen injection pressure was set to 6.0 bar (with injection valve closed), and the hydrogen was fed into the system at an ambient temperature of approximately $20^{\circ} \mathrm{C}$. A shaft encoder was fitted to the camshaft to measure engine speed and crank position. The cylinder pressure was measured using a fiber optic pressure sensor and the air mass flow was measured using a hot film flow meter. Finally, a meter was installed to measure the hydrogen flow rate. The experimental engine had a compression ratio of 17:1 and therefore to ensure autoignition of the hydrogen charge, the air inlet temperature was increased using a $2800 \mathrm{~W}$ electric heater controlled by a PID temperature controller. The hydrogen fuelled HCCI engine experimental setup is shown in Figure 1.

In order to avoid backfire, two fire gauzes were in-

\begin{tabular}{|l|l|}
\hline Engine manufacturer & Deutz \\
\hline Engine model & F1L511 \\
\hline Bore & $100 \mathrm{~mm}$ \\
\hline Stroke & $105 \mathrm{~mm}$ \\
\hline Swept volume & $825 \mathrm{~cm}^{3}$ \\
\hline Maximum engine speed & $3000 \mathrm{rpm}$ \\
\hline Compression ratio & $17: 1$ \\
\hline Intake air valve closes: & 59 degree ATDC \\
\hline Intake air valve opens: & 32 degree BTDC \\
\hline Intake air valve closed: & 269 degree \\
\hline Intake air valve open: & 91 degree \\
\hline Exhaust valve closes: & 32 degree ATDC \\
\hline Exhaust valve opens: & 71 degree BTDC \\
\hline Exhaust valve closed: & 257 degree \\
\hline Exhaust valve open: & 103 degree \\
\hline Valve overlap: & 27 degree \\
\hline
\end{tabular}

Table 1: Experimental test rig CI engine data.

stalled in the air inlet manifold and a flame trap on the hydrogen line, just after the needle valve and before the injector. To avoid hydrogen accumulation in the crankcase due to piston blow-by, a situation that can cause a crankcase explosion, a pipe was installed connecting the crankcase to the air inlet manifold, after the air heater.

\subsection{Engine control, data acquisition and performance monitoring system}

The engine control system was based on a microprocessor controller, running with specially developed software which allowed the timing and duration of the hydrogen injection to be set. The injection system implemented uses pulse width modulation (PWM) injection control using 8 bit precision and sampling at $20 \mathrm{kHz}$. A data acquisition system with a 16 bit resolution and $20 \mathrm{MHz}$ sampling frequency was used to acquire and process engine sensor and transducer signals. The data acquired was used to calculate real time performance parameters such as engine thermal efficiency, brake power, cylinder pressure, cycle mass of air and temperatures.

\section{Hydrogen fuelled HCCI engine experimental results}

The performance of the experimental engine test rig was investigated under varying operating conditions. With the engine running at $2200 \mathrm{rpm}$, air inlet temperature set at $93^{\circ} \mathrm{C}$ and a hydrogen flow rate of $90 \mathrm{dm}^{3} / \mathrm{min}$, HCCI mode of operation was tested.

\subsection{General performance}

With the objective of determining the leanest cylinder charge that the hydrogen fuelled HCCI engine can operate smoothly, a series of test were carried out with varying fuel-air ratio. Figure 2 illustrates the brake thermal efficiency as a function of the excess air ratio, $\lambda$. It can be seen that the engine is able to operate with extremely lean cylinder charges and still maintain a relatively high 


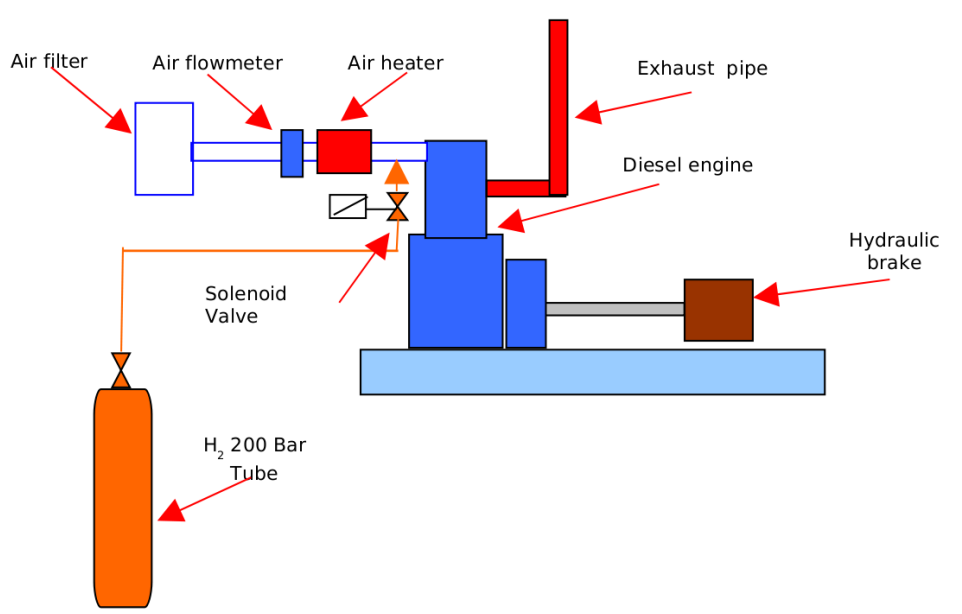

(a) Hydrogen fuelled HCCI engine experimental setup.

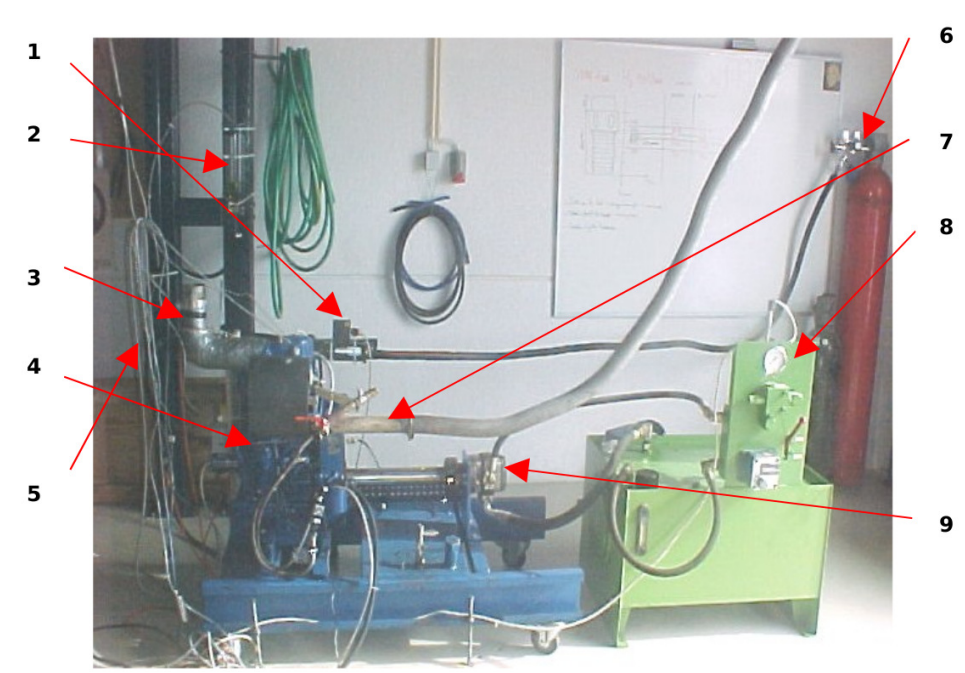

(b) Photograph of the experimental setup. 1: $\mathrm{H}_{2}$ flow meter; 2: diesel burette; 3 : air inlet manifold; 4: engine; 5: data acquisition system cables; 6: 200 bar $\mathrm{H}_{2}$ tube; 7: exhaust pipe; 8: hydraulic oil tank, brake control panel and pressure transmitter; 9: hydraulic brake pump.

Figure 1: Test engine experimental setup.

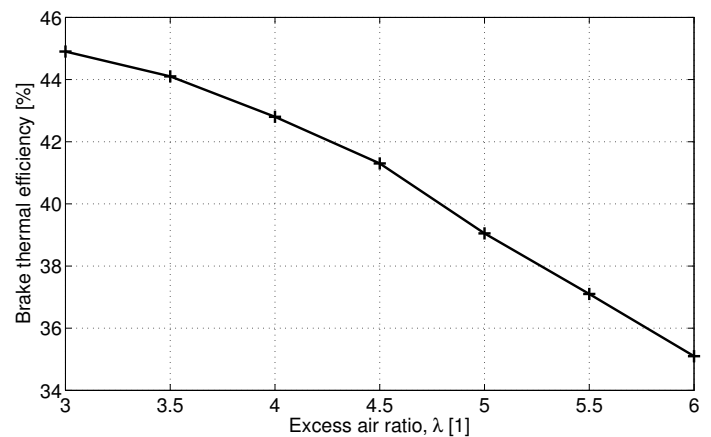

Figure 2: Engine brake thermal efficiency.

thermal efficiency when compared to conventional diesel engine operation.

Figure 3 shows the in-cylinder gas pressure for 10 consecutive engine cycles with the engine running at 2200 rpm with an air excess ratio of 3 . The engine brake thermal efficiency under these conditions was found to be ap- proximately $45 \%$. This is a significant increase in the thermal efficiency compared to its value under conventional operation using diesel fuel and is consistent with values reported in other research studies $[9,10,11]$. Some variation in maximum pressure between consecutive cycles were observed, due to the poor control of the combustion process that characterises the HCCI engine operation.

Cycle-to-cycle variations in cycle work output $(W)$ are commonly measured by the coefficient of variation, $\mathrm{COV}$, defined as

$$
\mathrm{COV}_{W}=\sigma_{W} / \operatorname{mean}(W)
$$

where $\sigma_{W}$ is the standard deviation of the cycle work and mean $(W)$ is the mean work output from the cycles. Heywood [6] stated that in automotive applications, vehicle driveability problems usually occur for $\mathrm{COV}_{W}$ values of above 10 per cent. For stationary engines, such as those used in generator sets, higher variation values could be tolerated.

Sets of 100 consecutive cycles taken at different operating conditions were analysed to establish the extent of the cycle-to-cycle variations in cycle work and in-cylinder 


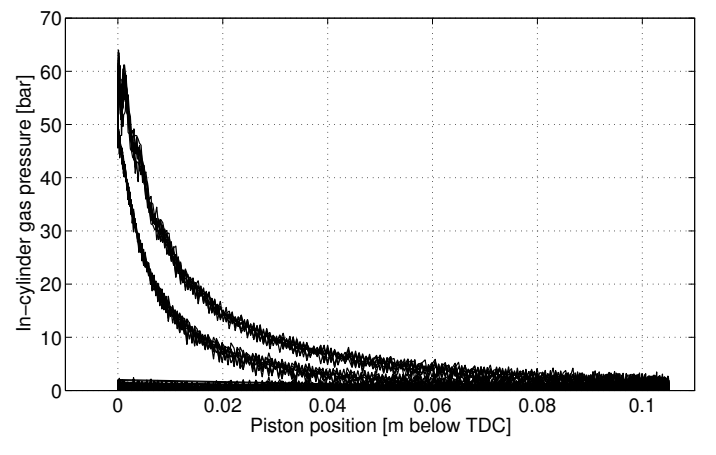

Figure 3: Cylinder pressure plots in HCCI mode.

gas pressure. It was found that between the highest and the lowest loads tested (i.e. an excess ratio of 3 and 6 respectively), the coefficient of variation in cycle work ranged from $7 \%$ to $23 \%$. These are acceptable values, particularly for the higher loads. The variations in peak in-cylinder gas pressure were somewhat higher, ranging from $15 \%$ to $25 \%$ in the same load interval. This is due to the high pressure rise shortly after ignition, giving high variations in peak pressure from only minor variations in ignition angle.

The in-cylinder pressure variation was examined to compare the combustion process for the hydrogen fuelled HCCI mode with the conventional diesel fuelled engine operation. Figure 4 shows engine in-cylinder pressure plots for one full cycle of these two operational modes with the engine at the same speed and load. Comparing the pressure traces, a significant difference in the combustion process between the two modes of operation can be seen. The peak cylinder pressure in hydrogen fuelled HCCI mode is on average more than $40 \%$ higher than that of the conventional diesel engine, and the fast pressure rise in the HCCI engine suggests a significantly higher rate of heat release (RHR).

\subsection{Effect of inlet air temperature}

The ignition angle $\left(\alpha_{\text {ign }}\right)$, governs the combustion process, and control of the ignition timing is of high importance in order to optimise engine operation. Figure 5a shows how the ignition timing is nearly linearly dependent on the inlet air temperature for the HCCI operational mode. This indicates that control of the inlet air temperature can be used to control ignition timing for the hydrogen fuelled HCCI engine. Figure 5b indicates that an increase in the air inlet temperature results in a decrease of engine power output. The brake thermal efficiency and the indicated mean effective pressure decrease with an increase in the air inlet temperature. This decrease is due to a reduction in the volumetric efficiency.

The impact of the inlet air temperature is further explored in Figure $5 \mathrm{c}$ with results for the engine operating in HCCI mode at a constant speed of $2000 \mathrm{rpm}$ and with a constant hydrogen mass flow rate of 90 litre per minute. The figure shows how the angle of maximum pressure $\left(\alpha_{\text {Pmax }}\right)$ and excess air ratio $(\lambda)$ vary with $T_{a}$. An increase in the temperature of the air at the cylinder inlet $T_{a}$, re-

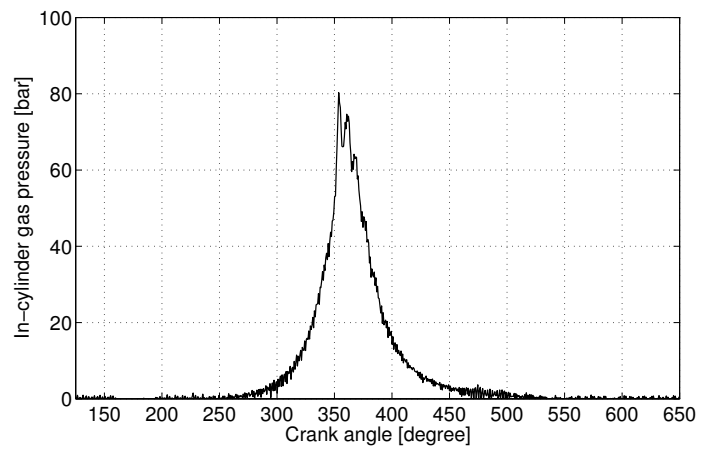

(a) In-cylinder pressure plot for $\mathrm{H}_{2} \mathrm{HCCI}$ operation.

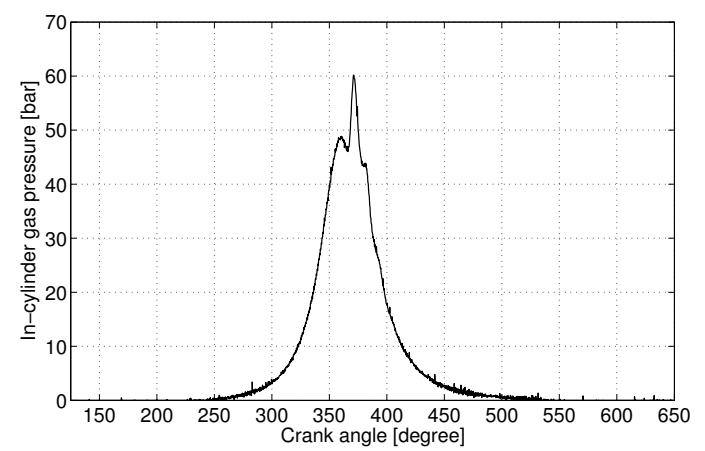

(b) In-cylinder pressure plot for conventional DI diesel operation.

Figure 4: Engine in-cylinder pressure plots.

sults in a decrease of the excess air ratio, and also has a significant effect on the angle at which the maximum combustion pressure occurs.

\subsection{Varying engine compression ratio}

It was found that the inlet air must be heated significantly to ensure hydrogen autoignition. Another method to ensure that the in-cylinder gases reach a state where hydrogen autoignites is to increase the engine compression ratio. Some variation in the compression ratio can be achieved controllable inlet and exhaust valves and varying the valve timings, however this requires actively actuated valves. A larger change in the compression ratio would require several engine design changes to achieve the increased compression pressure and for the components to cope with this new design specification. To analyse the impact of increasing the compression ratio a simulation study was carried out to determine the minimum inlet air temperature required for autoignition, as a function of the compression ratio. The simulation code uses single-zone, established models for gas flow, heat transfer and combustion, and includes ignition modelling based on the work of Tsugimura et al. [4] and heat transfer modelling based on the work of Woschni [12]. The simulation model was validated against experimental results from the engine at a compression ratio of $17: 1$, and will be used here to illustrate the relation between compression ratio and inlet air heating requirements.

Figure 6 shows the predicted required inlet air temperature for varying compression ratios, with the engine operating at $2000 \mathrm{rpm}$ and with hydrogen mass flow rate 9 gram per minute. It is seen that for very high compression 


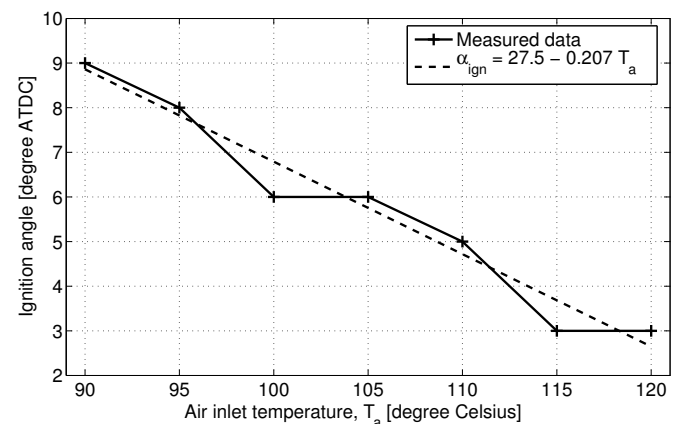

(a) Ignition angle for varying inlet air temperature.

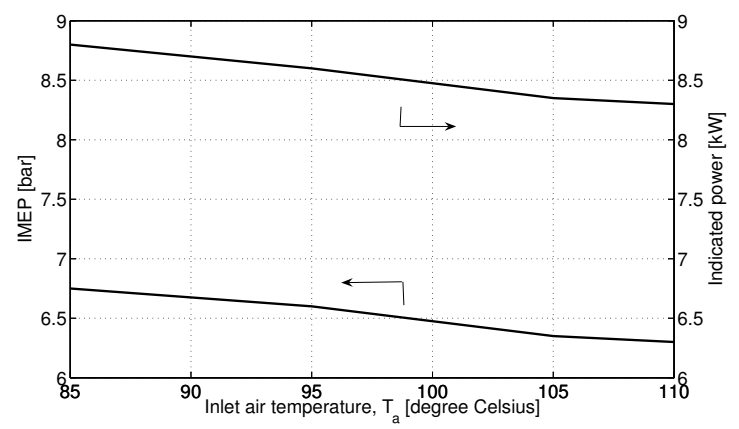

(b) Effect of inlet air temperature on engine power output.

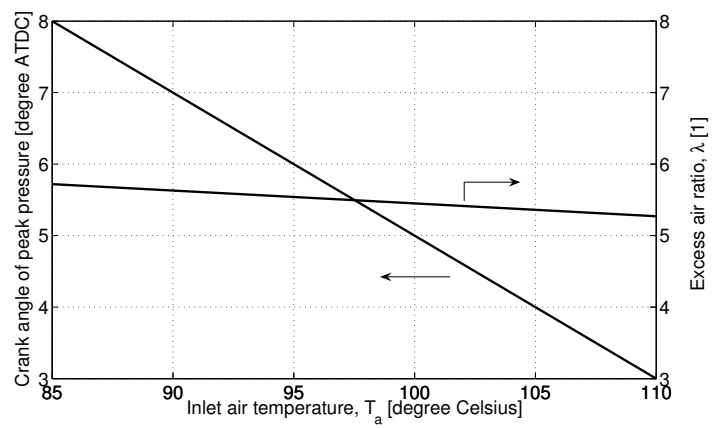

(c) Effect of inlet air temperature on peak pressure and excess air ratio.

Figure 5: Effect of inlet air temperature on HCCI engine operation.

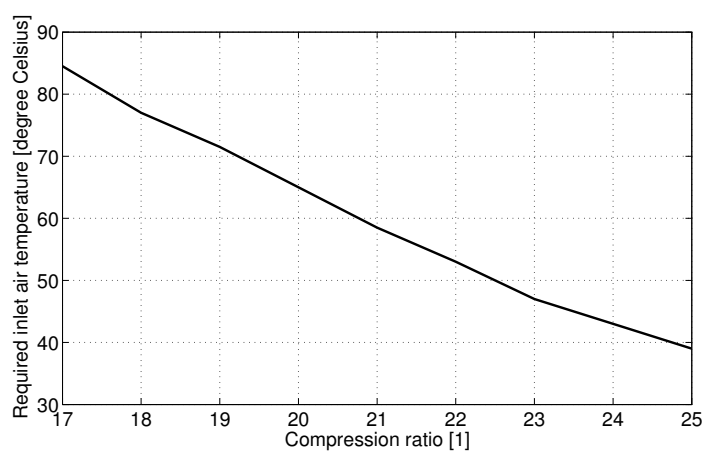

Figure 6: Required inlet air temperature for varying compression ratio.

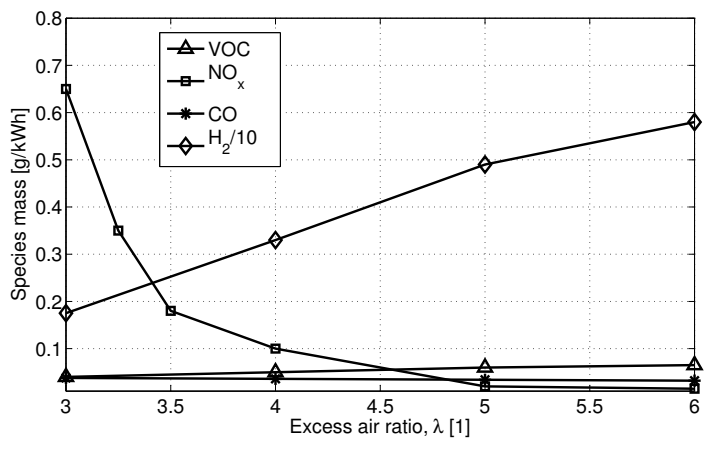

Figure 7: $\mathrm{H}_{2} \mathrm{HCCI}$ engine exhaust gas emissions levels.

ratios only a minimal increase in induced air temperature from the ambient conditions is required.

\subsection{Engine emissions}

The main source of nitrogen oxides $\left(\mathrm{NO}_{x}\right)$ emissions in internal combustion engines is the oxidation of atmospheric nitrogen, and the main reactions governing $\mathrm{NO}_{x}$ formation (commonly know as the Zeldovich mechanism) are strongly temperature dependent. The formation and destruction of $\mathrm{NO}_{x}$ in the combustion chamber is kinetically controlled, and as the temperature is rapidly reduced during the expansion stroke, the $\mathrm{NO}_{x}$ formed during the high-temperature parts of the cycle tend to 'freeze' at a level higher than the equilibrium level for the exhaust gases [13].

HCCI engines have shown significant reductions in $\mathrm{NO}_{x}$ emissions, due to lower peak gas temperatures. (High-temperature zones within the cylinder, such as the burning fuel spray in diesel engines, are eliminated.) Operation on high excess air ratios further reduces temperature levels and consequently $\mathrm{NO}_{x}$ emissions. For the hydrogen fuelled HCCI engine presented here, one would therefore expect significant reductions in $\mathrm{NO}_{x}$ emissions compared to when operated in conventional diesel engine mode.

The exhaust emissions were measured while the engine was operated in hydrogen fuelled HCCI mode at a speed of $2200 \mathrm{rpm}$ and $T_{a}$ of $100^{\circ} \mathrm{C}$. The results of the test are presented in Figure 7. As can be seen, the $\mathrm{NO}_{x}$ emissions increase sharply for $\lambda>3.5$, due to the increasing in-cylinder gas temperatures, and become negligible for higher values of $\lambda$. The $\mathrm{NO}_{x}$ levels are considerably lower that what would be expected for conventional diesel engine operation for all the cases investigated.

The levels of $\mathrm{CO}$ and unburnt hydrocarbons (VOC) emissions are fairly constant over the investigated load range. The levels of these emissions are negligible for the hydrogen engine, with the only carbon source being the burning of the lubricating oil.

Figure 7 also shows the presence of some hydrogen in the exhaust gases, and this is due to hydrogen slip which occurs during the valve overlap period and the nonoptimised hydrogen injection valve period. To minimise hydrogen slip, more accurate control of hydrogen injection is required. Values of exhaust emissions for the test 


\begin{tabular}{|l|l|l|}
\hline & $\begin{array}{l}\mathrm{H}_{2} \mathrm{HCCI} \text { engine } \\
\text { mode }\end{array}$ & $\begin{array}{l}\text { DI diesel engine } \\
\text { mode }\end{array}$ \\
\hline $\mathrm{NO}_{x}$ & $0.01 \mathrm{~g} / \mathrm{kWh}$ & $6.30 \mathrm{~g} / \mathrm{kWh}$ \\
\hline $\mathrm{CO}$ & $0.00 \mathrm{~g} / \mathrm{kWh}$ & $2.00 \mathrm{~g} / \mathrm{kWh}$ \\
\hline $\begin{array}{l}\text { Particulate } \\
\text { matter }\end{array}$ & $0.00 \mathrm{~g} / \mathrm{kWh}$ & $0.36 \mathrm{~g} / \mathrm{kWh}$ \\
\hline VOC & $0.02 \mathrm{~g} / \mathrm{kWh}$ & $0.50 \mathrm{~g} / \mathrm{kWh}$ \\
\hline
\end{tabular}

Table 2: Comparison of exhaust emissions for hydrogen fuelled HCCI and conventional diesel fuelled engine operation.

engine operating in hydrogen fuelled HCCI and conventional diesel fuelled engine modes are shown in Table 2.

\subsection{Mechanical loads and design demands}

It was found that both the maximum rate of pressure rise and the peak in-cylinder pressure were significantly higher in the HCCI hydrogen engine compared to operation in conventional diesel engine mode. Hence, when considering this type of operation, the mechanical load applied to the engine crank mechanism and piston ring needs to be considered.

From further analysis of the in-cylinder pressure results shown in Figure 4a, it was found that the mechanical load acting on the crank bearing and piston pin in hydrogen fuelled HCCI mode was approximately doubled when compared to the engine operating conventionally with diesel fuel.

As a consequence of the higher rates of pressure rise and peak pressures, additional design considerations must be given to the piston pin, crank bearings and piston rings, since their load carrying capacity should be taken into account if the reliability of the engine is to be maintained. As a practical rule, the ratio $P_{\max } / P_{\text {comp }}<1.5$ for standard diesel engine piston rings should be maintained. From the cylinder pressure measurements taken on the test engine, the ratio $P_{\max } / P_{\text {comp }}$ was calculated for several firing conditions. It was shown that it was difficult to achieve a ratio of less then three and therefore wider crank bearings and thicker piston rings would possibly need to be employed in hydrogen fuelled HCCI engines.

\section{Conclusions}

Experimental results from a single-cylinder diesel engine modified to run in homogeneous charge compression ignition mode using hydrogen fuel were presented. It was found that the peak in-cylinder pressures and the rates of pressure rise were higher in the HCCI hydrogen engine than for conventional operation on diesel fuel, limiting the HCCI engine to part load operation and potentially requiring design changes to maintain engine reliability. The fuel efficiency obtained was, however, significantly higher than that obtained when operating as a conventional diesel fuelled engine, and high efficiency was obtained even with very lean cylinder charges.

The inlet air had to be heated in order to ensure autoignition, and it was demonstrated that the inlet air temperature is the most useful variable to control ignition tim- ing. Engine emissions were measured and it was shown that negligible levels of all exhaust emissions were produced, including nitrogen oxides, compared to conventional diesel-fuelled operation.

\section{References}

[1] Antunes JMG, Roskilly AP. The use of H2 on compression ignition engines. In: Third European congress on economics and management of energy in industry, 6th-9th April 2004.

[2] Rottengruber H. Direct-injection hydrogen SI engine - operation strategy and power density potentials. SAE paper 2004-01-2927, 2004.

[3] Norbeck J, Heffel J, Durbin T, Montano M, Tabbara B, Bowden J. Hydrogen fuel for surface transportation. Society of Automotive Engineers, 1996.

[4] Tsujimura T, Mikami S, Achiha N, Tokunaga Y, Senda J, Fujimoto H. A study of direct injection diesel engine fueled with hydrogen. SAE paper 2003-01-0761, 2003.

[5] Naber JD, Siebers DL. Hydrogen combustion under diesel engine conditions. Int J Hydrogen Energy 1998:23:363-371.

[6] Heywood JB. Internal combustion engine fundamentals. McGraw Hill, 1988.

[7] Karim GA. Hydrogen as a spark ignition engine fuel. Int J Hydrogen Energy 2003:28:569-577.

[8] White CM, Steeper RR, Lutz AE. The hydrogenfueled internal combustion engine: a technical review. Int J Hydrogen Energy 2006:31:1292-1305.

[9] Stenlaas O, Egnell R, Johansson B, Mauss F. Hydrogen as homogeneous charge compression ignition engine fuel. SAE paper 2004-01-1976, 2004.

[10] Welch AB, Wallace JS. Performance characteristics of a hydrogen-fueled diesel engine with ignition assist. SAE paper 902070, 1990.

[11] Klein M, Andersson P, Eriksson LE. Compression Estimation From Simulated and Measured Cylinder Pressure. SAE paper 2002-01-0843, 2002.

[12] Woschni G. Universally applicable equation for the instantaneous heat transfer coefficient in the internal combustion engine. SAE paper 670931, 1967.

[13] Rottengrubber H. A study of the nitrogen oxide formation in a hydrogen diesel engine. (In German.) Hieronymus Buchreproduktion, ISBN 389791-047-0, 1999. 